\title{
Lung volume reduction surgery versus conservative treatment in severe emphysema
}

\author{
H. Wilkens*, S. Demertzis**, J. König***, C.K. Leitnaker*, H.J. Schäfers**, G.W. Sybrecht*
}

\begin{abstract}
Lung volume reduction surgery versus conservative treatment in severe emphysema. $H$. Wilkens, S. Demertzis, J. König, C.K. Leitnaker, H.J. Schäfers, G.W. Sybrecht. (C)ERS Journals Ltd 2000.

ABSTRACT: Lung volume reduction surgery (LVRS) has been proposed for patients with severe emphysema to improve dyspnoea and pulmonary function. It is unknown, however, whether prognosis and pulmonary function in these patients can be improved compared to conservative treatment.

The effect of LVRS and conservative therapy were compared prospectively in $\mathbf{5 7}$ patients with emphysema, who fulfilled the standard criteria for LVRS. The patients were divided into two groups according to their own decision. Patients in group 1 $(\mathrm{n}=29$, eight females, mean \pm SEM $58.8 \pm 1.7 \mathrm{yrs}$, forced expiratory volume in one second (FEV1) $27.6 \pm 1.3 \%$ of the predicted value) underwent LVRS. Patients in group 2 $(\mathrm{n}=\mathbf{2 8}$, five females, $58.5 \pm 1.8$ yrs, FEV1 $30.8 \pm 1.4 \%$ pred) preferred to postpone LVRS. There were no significant differences in lung function between the two groups at baseline; however, there was a tendency towards better functional status in the control group. The control group had a better modified Medical Research Council (MMRC) dyspnea score $(3.1 \pm 0.15$ versus $3.5 \pm 0.1, p<0.04)$.

Model-based comparisons were used to estimate the differences between the two groups over 18 months. Significant improvements were observed in the LVRS group compared to the control group in FEV1, total lung capacity (TLC), Residual volume (RV), MMRC dyspnea score and 6-min walking distance on all follow up visits. The estimated difference in FEV1 was $33 \%(95 \%$ confidence interval $13-58 \% ; p>0.0001)$, in TLC 12.9\% (7.9-18.8\%; $p>0.0001)$, in RV 60.9\% 32.6-89.2\%; $p>0.0001)$, in 6-min walking distance $230 \mathrm{~m}(138-322 \mathrm{~m} ; \mathrm{p}<0.002)$ and in MMRC dyspnoea score 1.17 (0.79-1.55; $\mathrm{p}<0.0001)$.

In conclusion, lung volume reduction surgery is more effective than conservative treatment for the improvement of dyspnoea, lung function and exercise capacity in selected patients with severe emphysema.
\end{abstract}

Eur Respir J 2000; 16: 1043-1049.

\author{
Abteilungen *Innere Medizin V, \\ **Thorax- und Herz-Gefäßchirurgie, and \\ ***Biometrie, Universitätskliniken des \\ Saarlandes, Homburg/Saar, Germany.
}

Correspondence: H. Wilkens

Medizinische Klinik V-Pneumologie

Universitätskliniken des Saarlandes

D-66421 Homburg/Saar

Germany

Fax: 496841163645

Keywords: Conservative treatment emphysema

lung volume reduction surgery

Received: July 72000

Accepted after revision September 62000
Emphysema is a progressive disease that ultimately leads to disabling dyspnoea and exercise limitation with substantial morbidity and reduced quality of life. Currently, there is no effective therapy for the irreversible airflow obstruction that results from the loss of elastic recoil with hyperinflation except smoking cessation. Thus, despite maximum conservative treatment, patients ultimately develop progressive respiratory failure, in many instances primarily related to the degree of hyperinflation of the lung.

Recently, lung volume reduction surgery (LVRS) has been reintroduced as a surgical treatment option for emphysema [1-4]. It reduces the overall lung volume by multiple wedge excisions of the most diseased portions of the lung. The exact physiological effect of LVRS has not been investigated in full detail [5]. Possible benefits of reduction of hyperinflation are restoration of the elastic recoil of the lung $[5,6]$ and improvement in the economics of the work of breathing [5, 7]. Marked improvements dyspnoea, exercise ability and quality of life have been reported [8-11]. However, it remains to be shown whether the morbidity and mortality associated with surgical treatment of emphysema are at least equal or superior to optimal conservative treatment [12]. Fur- thermore, the duration of improvement and the long-term outcome after LVRS are unclear.

Patients with dyspnoea often limit their physical activity. This inactivity leads to progressive deconditioning and can initiate a vicious cycle, with dyspnoea arising as a result of continuously reduced physical demands. Muscular rehabilitation has been documented as an effective means of treatment of chronic obstructive pulmonary disease (COPD) [13]. A number of investigations have documented both improvements in exercise ability and quality of life $[14,15]$. Pulmonary rehabilitation is increasingly being recognized as an important part of the management of patients with COPD and has now been accepted into routine clinical practice.

LVRS has been combined with rehabilitation in most instances [16]. Critics of this surgical approach to emphysema have argued that no data currently exist comparing the relative effects of muscular rehabilitation alone with LVRS.

The present study attempted to evaluate the relative treatment effect of LVRS in a prospective clinical trial in patients with end-stage pulmonary emphysema. This was compared to standard conservative therapy. 


\section{Patients and methods}

Over a 2-yr period (October 1995-October 1997), 90 patients with terminal obstructive lung disease were assessed for potential LVRS. Of these, 57 fulfilled the criteria for LVRS and were entered into the study.

The initial evaluation included pulmonary function tests (body plethysmography and determination of the diffusing capacity of the lung for carbon monoxide (DL,CO), determination of 6-min walking distance and dyspnoea score, echocardiography, right-heart catheterization and coronary angiography. Radiological evaluation consisted of chest radiography with posterior/anterior and lateral views during inspiration and expiration. The distribution of emphysema was assessed by ventilation perfusion scintigraphy and high-resolution computed tomography of the lungs. In addition, three density masks were obtained at the apices, bifurcation and bases of the lungs for identification of target areas. [17].

During the initial inpatients stay medical therapy was optimized with adjustments to theophylline and inhaled $\beta_{2}$-sympathomimetic and anticholinergic therapy and withdrawal of oral steroids. Four patients were kept on a maintenance dose of oral steroids $\left(5 \mathrm{mg}\right.$ prednisolone $\cdot$ day $\left.^{-1}\right)$.

\section{Inclusion criteria}

The characteristics of the study patients are shown in table 1 . The following criteria were required for study entry: dyspnoea at rest or with minimal exertion despite maximal medical therapy (modified Medical Research Council (MMRC) dyspnoea score of $\geq 3.0$ on a $0-4$ scale), total lung capacity (TLC) determined by body plethysmography of $\geq 120 \%$ of the predicted value, difference in TLC determined by body plethysmography or the helium single-breath method of $\geq 1.5 \mathrm{~L}$, residual volume (RV) of $>200 \%$ pred and smoking cessation for $\geq 3$ months.

\section{Exclusion criteria}

Patients who did not fulfill the inclusion criteria for LVRS were excluded from the investigation. They were also excluded if they had bullous disease $(>20 \%$ of the hemithorax), clinically dominant bronchiectasis or chronic bronchitis, a mean pulmonary artery pressure of $>35$ $\mathrm{mmHg}$, severe hypercapnia (arterial carbon dioxide tension $\left.\left(P \mathrm{a}, \mathrm{CO}_{2}\right) \geq 6.5 \mathrm{kPa}\right)$ or malignancies.

Table 1. - Clinical characteristics, dyspnoea score and exercise data of lung volume reduction surgery (LVRS) and control patients

\begin{tabular}{lccc}
\hline & LVRS & Control & p-value \\
\hline Age yrs & $58.8 \pm 1.7$ & $58.5 \pm 1.8$ & \\
& $(40-72)$ & $(33-77)$ & \\
Females/males n & $8 / 21$ & $5 / 23$ & \\
$\alpha_{1}$-AT deficiency n & 4 & 3 & \\
Oxygen supplementation* $\mathrm{n}$ & 16 & 15 & \\
MMRC dyspnoea score & $3.5 \pm 0.1$ & $3.1 \pm 0.15$ & $<0.04$ \\
6-min walking distance $\mathrm{m}$ & $236 \pm 34$ & $326 \pm 36$ & 0.06 \\
\hline
\end{tabular}

Data are presented as absolute values or mean \pm SEM with or without range in parentheses. *: continuous or intermittent. $\alpha_{1}$ : $\alpha_{1}$-antitrypsin; MMRC: modified Medical Research Council.
Thirty-three patients were excluded due to the presence of one or more exclusion criteria: chronic productive bronchitis $(n=22)$, hyperinflation with a TLC of $<120 \%$ pred $(n=10)$, MMRC dyspnoea score of $<3.0 \quad(n=8)$, bullous disease $(n=4)$, severe hypercapnia $(n=6)$, mean pulmonary artery pressure $>35 \mathrm{mmHg}(\mathrm{n}=1)$ or a continued history of smoking $(n=6)$.

\section{Subjects}

Fifty-seven consecutive patients (10 female) fulfilled the inclusion criteria and gave informed consent for the present investigation. The mean \pm SEM age was $59 \pm 0.41 \mathrm{yrs}$ (range 33-77 yrs). All patients suffered from severe dyspnoea despite maximal medical therapy with a an MMRC dyspnoea score of $3.3 \pm 0.06$.

The patients had severe airway obstruction, as documented by serial lung function tests with a forced expiratory volume in one second (FEV1) of $0.848 \pm 0.029$ L (29\% pred). All patients showed severe hyperinflation of the lungs with a TLC of $135 \pm 1.6 \%$ pred, an RV of $271 \pm 8.5 \%$ pred and an RV/TLC of $71 \pm 1.0 \%$. All were previous smokers. Seven patients also showed $\alpha_{1}$ antitrypsin deficiency.

\section{Study design}

The 57 patients were studied prospectively. Many patients came with the clear intention of undergoing LVRS. Therefore, true randomization appeared psychologically impossible to perform. Thus, following an initial 6-week rehabilitation period, all patients were advised to undergo further rehabilitation alone or, if otherwise, desired at least to postpone LVRS. On the basis of the patients' decision two groups were formed. Patients in group $1 \quad(n=29)$ underwent LVRS after the initial rehabilitation protocol. The patients in group $2(n=28)$ agreed to be treated with standard treatment alone or postpone LVRS by $\geq 12$ months. All patients were followed using pulmonary function testing and objective investigation of exercise tolerance.

\section{Surgical technique}

The procedure was performed in most patients as a bilateral procedure via a median sternotomy. Six patients were approached unilaterally via a limited anterolateral thoracotomy because of previous pleurodesis $(n=2)$, previous thoracic surgery $(n=2)$ or the distribution of emphysema $(n=2)$. All procedures were performed by two surgeons under general anaesthesia. The resections were performed using staples (Ethicon, Hamburg, Germany) reinforced with bovine pericardium (Medtronic, Düsseldorf, Germany). The target areas were selected according to preoperative diagnostic studies. During the procedure, the surgeons judged the potential of the different regions of the lung to absorb oxygen and develop atelectasis. Two thoracic drains were placed in each hemithorax. According to the extent of air leakage, no suction at all or mild suction was applied. 
The patients were extubated as soon as possible after completion of the procedure. All patients were treated with a combined analgesic regimen. Rigorous pulmonary physical treatment was initiated immediately after extubation, focusing on adequate clearance of bronchial secretions.

\section{Pulmonary function tests}

Pulmonary function testing included spirometry, body plethysmography, determination of $D \mathrm{~L}, \mathrm{CO}$ and resting room-air arterial blood gas analyses.

Pulmonary function studies were performed after administration of an inhaled bronchodilator $(400 \mu \mathrm{g}$ salbutamol)

Lung volumes were measured in a whole-body plethysmograph (Jäger Masterlab, Würzburg, Germany). Dyspnoea was assessed using the MMRC dyspnoea score [18], by which shortness of breath is rated 0-4 according to increase in symptom severity. The 6-min walking distance was measured in all patients on a 70-m floor after providing standard instructions [19]. Each patient was asked to walk as far as possible in 6 min with rest periods if necessary. No encouragement was given during the test. All patients were familiar with the 6-min walking test before study entry. Patients on continuous oxygen therapy performed the walk with supplemental oxygen.

\section{Pulmonary rehabilitation}

All patients joined a pulmonary rehabilitation programme during the inpatient stay for initial evaluation (2-6 weeks) with exercise training and education about medication, oxygen therapy and nutrition [20, 21]. For each patient, an individualized training programme was set up, including lower and upper extremity exercise conditioning (walking, bicycle training and weight lifting), breathing retraining and bronchial hygiene instruction. Patients were encouraged to continue the exercise programme at home.

\section{Clinical follow-up}

After completion of the initial 6-week rehabilitation phase measurements were performed in all patients. These measurements were taken as baseline for both treatment groups. Surgery was performed within 5 days after baseline measurement. Patients were followed every 3 months for 18 months. The first control visit occurred 4-6 weeks after LVRS, the same follow-up protocol was used throughout the study.

Outcome parameters included FEV1 as the primary outcome measure. The secondary outcome measures were lung volumes, MMRC dyspnea score, 6-min walking distance and blood gas analysis results.

\section{Statistical analysis}

All data are presented as mean \pm SEM or $95 \%$ confidence interval. A paired t-test was used to determine differences in lung function parameters, 6-min walking distance and
MMRC dyspnoea score between baseline and each followup period in the control and LVRS groups. A p-value of $<0.05$ was considered significant.

For comparison between the control and LVRS group, general linear mixed models were fitted for estimation of treatment effects in order to account for structural inhomogeneity at baseline as well as for missing observations during follow-up. Linear mixed models are a type of multiple linear regression model that allow for time dependency and missing observations during follow-up [22]. One type of model assumes a constant treatment effect over time, i.e. constant mean differences between the LVRS and control groups with respect to outcome variables. Another type of model allows for different treatment effects at each of the fixed follow-up time points. The same group of baseline variables was used in all fitted models.

The analysis was performed using SAS software (SAS Institute, Cary, NC, USA). Within each model, tests and confidence intervals for treatment effects are based on tand F-tests with approximated degrees of freedom, the ttest for estimation of the constant treatment effect and the F-test with five numerator degrees of freedom for testing constancy of treatment effect with time.

\section{Results}

\section{Patient characteristics}

There was no significant difference with regard to age, sex, lung volumes, expiratory flow rates, resting alveolar gas exchange or use of supplemental oxygen between the two groups (tables 1 and 2). However, there was tendency towards a better functional status in the control group at baseline. The control group had a better MMRC dyspnoea score ( $3.1 \pm 0.15$ versus $3.5 \pm 0.1$ (mean \pm SEM), $\mathrm{p}<0.04)$ than the LVRS group.

Every living patient was followed up for $>6$ months. No patients were lost to follow-up, although some

Table 2. - Preoperative lung function and gas exchange

\begin{tabular}{lccc}
\hline & LVRS & Control & p-value \\
\hline FEV1 L & $0.80 \pm 0.04$ & $0.895 \pm 0.04$ & NS \\
$\%$ pred & $27.6 \pm 1.3$ & $30.8 \pm 1.4$ & 0.085 \\
TLC & $8.52 \pm 0.26$ & $8.33 \pm 0.28$ & NS \\
$\%$ pred & $137 \pm 2.5$ & $133 \pm 2.1$ & NS \\
RV & $6.2 \pm 0.25$ & $5.8 \pm 0.26$ & NS \\
$\%$ pred & $286 \pm 10.5$ & $263 \pm 10$ & NS \\
FVC & $2.29 \pm 0.12$ & $2.7 \pm 0.2$ & NS \\
$\%$ pred & $60 \pm 3.1$ & $67 \pm 3.9$ & NS \\
MIP kPa & $4.86 \pm 0.44$ & $5.5 \pm 0.42$ & NS \\
$P_{\mathrm{a}, \mathrm{O}_{2}} \mathrm{kPa}$ & $8.7 \pm 0.3$ & $8.6 \pm 0.3$ & NS \\
$P_{\mathrm{a}, \mathrm{CO}} \mathrm{kPa}$ & $5.4 \pm 0.2$ & $5.41 \pm 0.144$ & NS \\
$D \mathrm{~L}, \mathrm{CO} \%$ pred & $42 \pm 3.2$ & $43 \pm 4.6$ & NS \\
\hline
\end{tabular}

LVRS: lung volume reduction surgery; FEV1: forced expiratory volume in one second; TLC: total lung capacity; RV: residual volume; FVC: forced vital capacity; MIP: maximal inspiratory mouth pressure; $\mathrm{Pa}, \mathrm{O}_{2}$ : arterial oxygen tension; $\mathrm{Pa}_{\mathrm{a}}, \mathrm{CO}_{2}$ : arterial carbon dioxide tension; $D$ L,CO: diffusing capacity of the lung for carbon monoxide; $\%$ pred: percentage of the predicted value; Ns: nonsignificant. 
tended to stretch the intervals between follow-up visits, such that not every patient was seen at every follow-up visit.

After 18 months, five control patients underwent LVRS. Their postoperative data are not included in the results.

\section{Mortality}

There was no early perioperative mortality ( $<30$ days). One patient had to be reintubated 3 days after LVRS and died, after an 8-month inpatients stay, from respiratory failure due to pneumonia. Fatal events in the LVRS and control groups are summarized in table 3 .

Lung volume reduction surgery versus conservative treatment

After LVRS, there was a significant improvement in FEV1 at each follow-up visit $(\mathrm{p}<0.04)$ (fig. 1).

Comparison of LVRS and control patients showed a significant effect of lung volume reduction surgery on FEV1 $(p<0.001)$. The baseline FEV1 of the control patients was higher than that of the LVRS patients. Nevertheless, after LVRS the FEV1 increased markedly in the surgical group compared with control patients (fig. 1).

Since not every patient was seen at every follow-up visit, a comparison of unadjusted data does not permit comment on the duration of the treatment effect. Therefore, a model based comparison using a general linear mixed model-including baseline log FEV1 was used. This analysis showed that the maximal increase in FEV1 was reached within the first 4-6 weeks, with a mean \pm SEM FEV1 increase of $0.2690 .047 \mathrm{~L}(\mathrm{p}<0.001)$ (fig. 2).

The mean increase in FEV1 was $28 \%$; however, there was large interindividual variation (range $-31-69 \%$ ). Fifty percent of patients showed an improvement in FEV1 of $\geq 31 \%$. After the first visit, a linear decrease in FEV1 of $0.115 \pm 0.03 \mathrm{~L} \cdot \mathrm{yr}^{-1}$ could be observed (fig. 2).

The rate of decrease was almost the same as that in the control group. The estimated difference between treatments was 33\% (13-58\%) with significant effects of treatment at all follow-up visits $(\mathrm{p}<0.01)$ (fig. 2, table 4).

Hyperinflation, measured by TLC and RV, was reduced significantly by LVRS $(\mathrm{p}<0.001)$. There were significant differences between the LVRS and control group at all follow-up visits $(\mathrm{p}<0.02)$, with an estimated difference

Table 3. - Mortality in the lung volume reduction surgery and control groups

\begin{tabular}{lrrl}
\hline $\begin{array}{l}\text { Patient } \\
\text { No. }\end{array}$ & $\begin{array}{c}\text { Age } \\
\text { yrs }\end{array}$ & $\begin{array}{l}\text { Survival Cause of death } \\
\text { months }\end{array}$ \\
\hline \multicolumn{4}{l}{ Lung volume } \\
12 & 43 & 21 & reduction surgery \\
19 & 69 & 14 & Relon perforation, respiratory failure \\
22 & 55 & 8 & Pneumonia failure \\
23 & 57 & 12 & Sepsis after lung transplantation \\
Control & & & \\
6 & 61 & 29 & Oesophageal carcinoma \\
11 & 51 & 24 & Respiratory failure \\
14 & 55 & 6 & Pneumonia \\
20 & 62 & 3 & Cardiac arrest \\
\hline
\end{tabular}

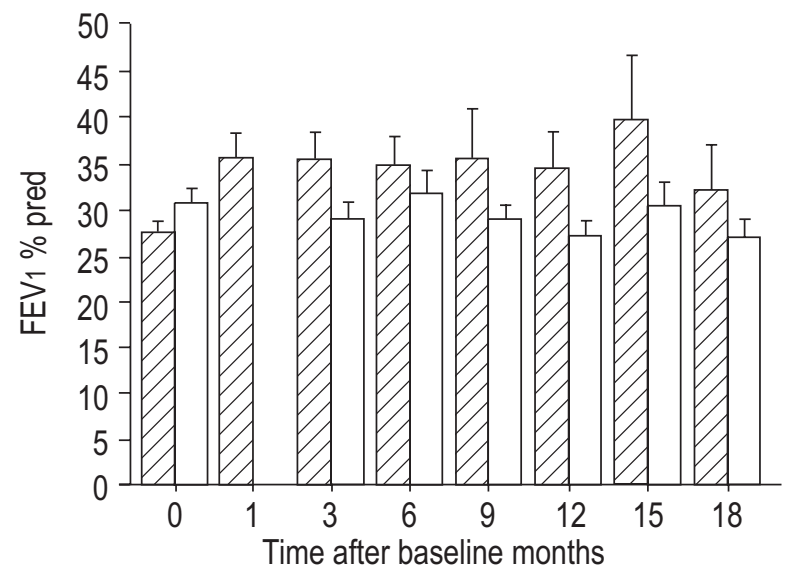

Fig. 1. - Unadjusted time course of forced expiratory volume in one second (FEV1) in the lung volume reduction surgery (LVRS, $\mathbb{Z}$ ) and control group $(\square)$. Data are presented as mean \pm SEM. Number of patients (LVRS/control): 0 months: 29/28; 1 month: 25/0; 3 months: 21/19; 6 months: $18 / 17$; 9 months: $13 / 15$; 12 months: $16 / 18$; 15 months: $8 / 10$; and 18 months: $13 / 13$. \% pred: percentage of the predicted value.

between treatments in TLC of $12.9 \%(7.9-18.8 \%)$ and in RV of $60.9 \%(32.6-89.2 \%)(\mathrm{p}=0.0001)$ (table 4$)$.

Maximal decrease was obtained within the first 4-6 weeks with a mean decrease in TLC of $22.1 \%$ and in RV of $80.4 \%$. Thereafter, a linear increase in TLC of $5.19 \pm 2.04 \% \cdot \mathrm{yr}^{-1}(\mathrm{p}=0.013)$ and in RV of $17.7 \pm 6.5 \% \cdot \mathrm{yr}^{-1}$ $(\mathrm{p}<0.01)$ were noted.

A significant effect of treatment on dyspnoea measured by MMRC dyspnoea score was observed $(\mathrm{p}<0.002)$ (fig. 3 ). Although the control group had a significantly better baseline dyspnoea score than the LVRS group (3.1 versus $3.5, \mathrm{p}<0.02)$, lower dyspnoea scores were observed at all follow-up visits in the LVRS group $(\mathrm{p}<0.01)$.

There was a significant effect of surgery on 6-min walking distance compared to conservative treatment $(p<0.003)$. Although the baseline 6 -min walking distance of the LVRS group was lower, marked improvement was observed at all follow-up visits compared to the control group (fig. 4), with an estimated difference between treatments of $230 \mathrm{~m}(138-322 \mathrm{~m})(\mathrm{p}<0.002)$ (table 4).

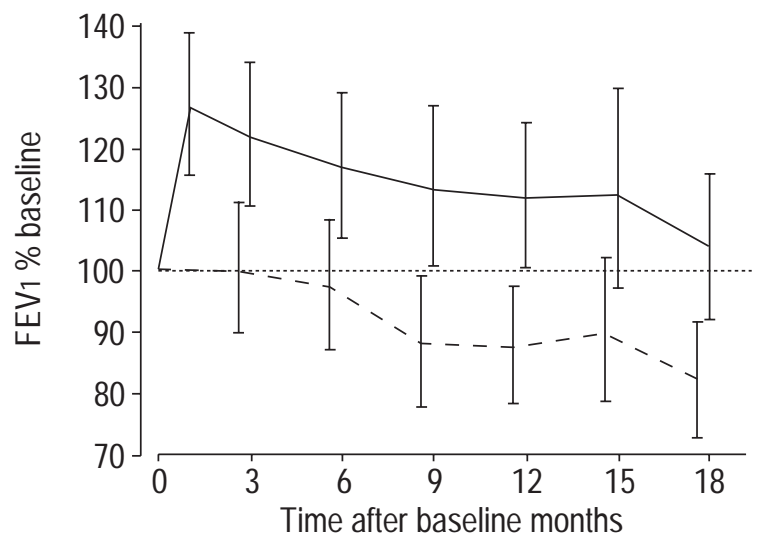

Fig. 2. - Time course of forced expiratory volume in one second (FEV1) by model-based comparison using a general linear mixed model including baseline log FEV1 in the lung volume reduction surgery (-) and control group (- - ). Vertical bars represent $95 \%$ confidence intervals. 
Table 4. - Size of treatment effect adjusted for baseline variables

\begin{tabular}{lcc}
\hline & Size of effect* & p-value \\
\hline FEV1 \% & $33(13-58)$ & 0.0001 \\
6-min walking distance $\mathrm{m}$ & $230(138-322)$ & 0.0015 \\
MMRC dyspnoea score & $-1.17(-0.79--1.55)$ & 0.0001 \\
TLC \% pred & $-12.9(-17.8--7.9)$ & 0.0001 \\
RV \% & $60.9(-89.2--32.6)$ & 0.0001 \\
\hline
\end{tabular}

Data are presented with $95 \%$ confidence intervals in parentheses. *: difference from control group; FEV1: forced expiratory volume in one second; MMRC: modified Medical Research Council; TLC: total lung capacity; RV: residual volume; \% pred: percentage of the predicted value.

No significant effect of surgery was found on $D \mathrm{~L}, \mathrm{CO}$, arterial oxygen tension or $\mathrm{Pa}_{3} \mathrm{CO}_{2}$, although there was a tendency towards better values in the LVRS group.

There was no significant influence of time on the treatment differences between the LVRS and control group for all calculated parameters (table 4).

\section{Conservative treatment}

In the control group, no significant changes were observed in MMRC dyspnoea score or 6-min walking distance during 18 months of conservative treatment, whereas deterioration could be observed in FEV1, TLC and RV within the study period. There was a decrease in FEV1 of $115 \pm 0.03 \mathrm{~mL} \cdot \mathrm{yr}^{-1}(\mathrm{p}=0.0001)$ with an increase in TLC of $3.8 \pm 2.04 \% \cdot \mathrm{yr}^{-1}(\mathrm{p}=0.033)$ and in RV of $12.9 \pm$ $5.6 \% \cdot \mathrm{yr}^{-1}(\mathrm{p}<0.01)$.

Estimation of time gained by lung volume reduction surgery

$\log _{10}$ FEV1 (\% pred) increased by $0.1086 \pm 0.0179$ from baseline to the first postoperative visit. The decrease thereafter was $0.00497 \pm 0.00133 \% \cdot$ month $^{-1}$ until the 18 month visit. This corresponds to a time gain of 21.9

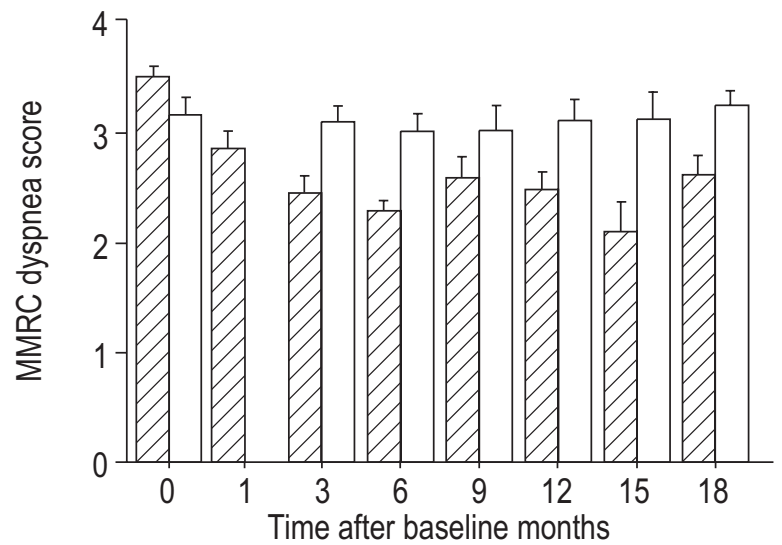

Fig. 3. - Unadjusted time course of modified Medical Research Council (MMRC) dyspnoea score lung volume reduction surgery (LVRS, $\mathbb{Z}$ ) and control group $(\square)$. Data are presented as mean \pm SEM. Number of patients (LVRS/control): 0 months: 29/28; 1 month: $25 / 0$; 3 months: $21 / 19 ; 6$ months: $18 / 17$; 9 months: $13 / 15$; 12 months: $16 / 18$; 15 months: $8 / 10$; and 18 months: $13 / 13$

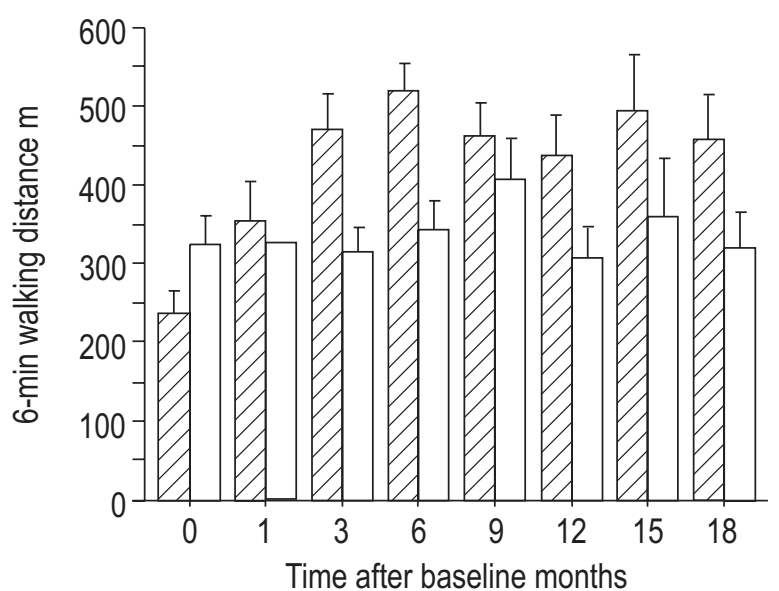

Fig. 4. - Unadjusted time course of 6-min walking distance in the lung volume reduction surgery (LVRS, $\mathbb{Z}$ ) and control group $(\square)$. Data are presented as mean \pm SEM. Number of patients (LVRS/control): 0 months: 29/28; 1 month: 25/0; 3 months: 21/19; 6 months: 18/17; 9 months: 13 / 15; 12 months: $16 / 18 ; 15$ months: $8 / 10$; and 18 months: $13 / 13$.

$(0.1086 / 0.00497)$ months until baseline FEV1 are reached again (fig. 2).

\section{Discussion}

In the present study, LVRS patients exhibited markedly better functional status at follow-up than control patients despite worse baseline values. Significant improvement in pulmonary function was found in the LVRS patients. This included improvement in expired volumes (FEV1 and FVC) as well as decreases in static volumes (TLC and RV), and improved exercise capacity and dyspnoea.

No changes in dyspnoea and 6-min walking distance with minor changes in TLC and RV were observed in control patients under optimal conservative treatment within 1.5 yrs despite decline in FEV1 of $115 \mathrm{~mL} \cdot \mathrm{yr}^{-1}$. During this time, more clinical deterioration would have been expected in this group of severely disabled patients $[23,24]$. The relatively stable course of the control patients might be due to effects of continuing physical training and motivation by the option of LVRS. Since both groups received the same conservative treatment, LVRS was shown to have a significant additional effect on lung function and exercise capacity compared to conservative therapy.

In the present patients, the mean improvements in FEV1 of $28 \%$ were less dramatic than those reported by most groups [10, 25-27], whereas similar reductions in lung hyperinflation and decreases in dyspnoea score with relatively high increases in 6-min walking distance were found compared to the results of other groups [1, 10, 27]. Patient selection and analysis of data might explain these differences $[27,28]$. The present patients had mostly homogeneous emphysema, whereas, in other groups, patients with bullous disease were included [29]. Analysis of data was performed at scheduled time points in the present study; other groups may have compared preoperative lung function with best postoperative values. Thus LVRS in the present patients resulted in moderate improvement in FEV1 with marked increases in exercise tolerance and improvement of dyspnoea. 
A number of studies have been published supporting the assumption of COOPER et al. [10] that LVRS offers benefits not achievable by optimal conservative treatment for highly selected patients with severe emphysema. Additionally, the results of these studies have been evaluated in recent reviews $[11,27]$, indicating that significant short-term benefits occurred across a range of outcomes which appeared to continue into the longer term. However, data comparing LVRS to optimal conservative treatment will be lacking [11] until the results of the ongoing National Emphysema Treatment Trial (NETT) [30] are available. A retrospective study has been published comparing 22 LVRS candidates denied operation because of withdrawal of Medicare funding with 65 LVRS recipients [31]. Similar to the present results, those patients denied operation experienced progressive worsening of spirometric results, whereas LVRS patients experienced sustained improvements. Three-year survival was $82 \%$ for the surgical group and $64 \%$ for the medical group. In a prospective study, 37 patients were randomized after 8 weeks of rehabilitation, to either LVRS or a further 3 months of rehabilitation [32]. It was shown that LVRS, in addition to rehabilitation, improved lung function, gas exchange and quality of life compared with pulmonary rehabilitation alone, 3 months after LVRS. A recent randomized study compared surgery to continued medical treatment in 48 patients [33]. FEV1, shuttle walking distance and quality of life were improved in the LVRS group and decreased in the medical group at 6 and 12 months of follow-up. However, there was a relatively high rate of inpatient death; four of 24 patients died within the first 3 months after surgery.

To the authors' knowledge, the present study is the first prospective investigation with a follow-up of $>1 \mathrm{yr}$ comparing LVRS to conservative treatment in patients fullfilling the inclusion criteria for LVRS. There are, however, several limitations to the present study. One crucial point is the study design, which was prospective but not randomized. Due to enthusiastic reports of LVRS in the lay press, many patients came with the clear intention of being treated i.e. of undergoing LVRS. In a number of patients, it was impossible to withhold surgery in the face of a strong patient decision and not to have the patient turn to another centre to undergo surgery. Therefore, in order to generate a control group, it was proposed that all patients postpone their surgery, and leaving the ultimate decision to the patient. A bias thus cannot be excluded, since patients with more pronounced symptoms may have had a stronger preference towards LVRS. The sicker patients tended to decide on immediate operation. Nevertheless, their functional status was better during the following 18 months than that of the control group, confirming the efficacy of surgical treatment.

A second limitation of the present study is the number of patients. It is very difficult to achieve follow-up at regular repeated intervals in this group of patients [34]. It was not easy to motivate patients to come for follow-up visits over long distances, if no subjective changes had occurred, although great care was taken to keep in contact with patients, at least by telephone, thus not every patient was seen at every follow-up date. This problem is mainly responsible for the variations seen in figures 1,3 and 4 . A model-based comparison using a general linear mixed model adjusted for baseline values (fig. 2, table 4) was utilized to account for heterogenity in baseline variables as well as for missing values during follow-up. The results indicate that the treatment effect was constant throughout the observation period.

Owing to sample size, the present data do not allow an assessment of the influence of LVRS on mortality in emphysema patients. Larger studies are necessary in order to demonstrate whether the prognosis can be improved by LVRS, especially with regard to perioperative mortality. Operative mortality rates have been reported as $0-8 \%$, with higher rates in the most severely affected patients $[12,33]$. It has been shown that there is a correlation between the magnitude of short-term improvement in FEV1 and the rate of deterioration, with more rapid decline in FEV1 in those patients with the best initial improvement [34]. However, in the present patients, the annual decrease in FEV1 seemed not to be not altered by LVRS, with an identical rate of decline in FEV 1 in the surgical and medical treatment groups. The same observation was made in a recent randomized trial, with a yearly decrease in FEV 1 of $100 \mathrm{~mL}$, irrespective of surgical or medical treatment [33].

There was large interindividual variability in the response to LVRS. The majority of the present patients showed a $>20 \%$ improvement in FEV1. However, several patients without improvement in FEV1 $(<15 \%)$ reported marked improvement in functional capacity.

Patient selection for LVRS is difficult despite clearly formulated inclusion and exclusion criteria [35-38]. The predictability of objective and subjective postoperative results remains poor, since no good selection criteria are available to data to distinguish between those patients who will benefit from LVRS and those who will not.

The relatively stable course of the control patients deserves further consideration since it is unclear to data for how long the effect of LVRS can be maintained and which patients will respond best. Therefore, the optimal time point for LVRS remains to be determined. The choice between continuing pulmonary rehabilitation and immediate LVRS is difficult. In the standard treatment group, the possibility of deterioration of disease along with increasing perioperative risks due to delayed LVRS should be considered. Conversely the duration and degree of improvement after immediate LVRS cannot be predicted for individual patients. The best timing of LVRS is an individual decision that should be guided by the clinical course and response to intensive pulmonary rehabilitation.

In summary, it was found that lung volume reduction surgery was superior to conservative therapy in the present patients. Since these data were obtained from a nonrandomized study, bias cannot be excluded. However, the present study indicates that lung volume reduction surgery may be more effective than conservative treatment in improving dyspnoea, lung function and exercise capacity in patients with severe emphysema.

\section{References}

1. Cooper J, Patterson G. Lung-volume reduction surgery for severe emphysema. Chest Surg Clin N Am 1995; 5: 815-831.

2. Cooper J, Trulock E, Triantafillou A, et al. Bilateral pneumectomy (volume reduction) for chronic obstructive 
pulmonary disease. J Thorac Cardiovasc Surg 1995; 109: 106-116 (discussion 116-119).

3. Deslauriers J. History of surgery for emphysema. Semin Thorac Cardiovasc Surg 1996; 8: 43-51.

4. Brantigan O, Mueller E. Surgical treatment of pulmonary emphysema. Am Surg 1957; 23: 789-804.

5. Marchand E, Gayan-Ramirez G, De Leyn P, Decramer M. Physiological basis of improvement after lung volume reduction surgery for severe emphysema: where are we? Eur Respir J 1999; 13: 686-696.

6. Sciurba F, Rogers R, Keenan R, et al. Improvement in pulmonary function and elastic recoil after lung-reduction surgery for diffuse emphysema. N Engl J Med 1996; 334: 1095-1099.

7. Criner G, Cordova F, Leyenson V, et al. Effect of lung volume reduction surgery on diaphragm strength. Am J Respir Crit Care Med 1998; 157: 1578-1585.

8. Leuenberger P, Anderhub H, Brandli O, et al. Management 1997 of chronic obstructive pulmonary disease. Working Group of the Swiss Society of Pneumology. Schweiz Med Wochenschr 1997; 127: 766-782.

9. Gaissert H, Trulock E, Cooper J, Sundaresan R, Patterson G. Comparison of early functional results after volume reduction or lung transplantation for chronic obstructive pulmonary disease. J Thorac Cardiovasc Surg 1996; 111: 296-306 (discussion 306-307).

10. Cooper J, Patterson G, Sundaresan R, et al. Results of 150 consecutive bilateral lung volume reduction procedures in patients with severe emphysema. $J$ Thorac Cardiovasc Surg 1996; 112: 1319-1329 (discussion 1329-1330).

11. Young J, Fry-Smith A, Hyde C. Lung volume reduction surgery (LVRS) for chronic obstructive pulmonary disease (COPD) with underlying severe emphysema. Thorax 1999; 54: 779-789.

12. Brenner M, McKenna RJJ, Chen JC, et al. Survival following bilateral staple lung volume reduction surgery for emphysema. Chest 1999; 115: 390-396.

13. Celli B. Pulmonary rehabilitation for COPD. A practical approach for improving ventilatory conditioning. Postgrad Med 1998; 103: 173-176.

14. Goldstein R, Gort E, Stubbing D. Randomized, controlled trial of respiratory rehabilitation. Lancet 1994; 344: 1394-1397.

15. Lacasse Y, Wong E, Guyatt G, King D, Cook D, Goldstein R. Meta-analysis of respiratory rehabilitation in chronic obstructive pulmonary disease. Lancet 1996; 348 : 1115-1119.

16. Moy ML, Ingenito EP, Mentzer SJ, Evans RB, Reilly JJJ. Health-related quality of life improves following pulmonary rehabilitation and lung volume reduction surgery. Chest 1999; 115: 383-389.

17. Müller N, Staples C, Miller R, Abboud R. "Density mask". An objective method to quantitate emphysema using computed tomography. Chest 1988; 94: 782-787.

18. Task group on screening for respiratory disease in occupational settings. Official statement of the American Thoracic Society. Am Rev Respir Dis 1982; 126: 952-956.

19. Guyatt GH, Pugsley SO, Sullivan MJ, et al. Effect of encouragement on walking test performance. Thorax 1984; 39: 818-822.

20. Joint ACCP/AACVPR Pulmonary Rehabilitation Guidelines Panel. Pulmonary rehabilitation: joint ACCP/ AACVPR evidence-based guidelines. Chest 1997; 112: 1363-1396.

21. Casaburi R. Exercise training in chronic obstructive lung disease. In: Casaburi R, Petty $\mathrm{T}$, eds. Principles and Practice of Pulmonary Rehabilitation. Philadelphia, PA, Saunders, 1993.

22. Diggle P, Liang K, Zegler S. Analysis of Longitudinal Data. Oxford, Clarendon Press, 1994.

23. Hudson L. Survival data in patients with acute and chronic lung disease. Am Rev Respir Dis 1990; 140: 519-524.

24. Pinto-Plato V, Girish M, Taylor J, Celli B. Natural decline in the six-minute walking distance (6MWD) in patients with COPD. Am J Respir Crit Care Med 1998; 157: A20.

25. Russi E, Stammberger U, Weder W. Lung volume reduction surgery for emphysema. Eur Respir J 1997; 10: 208-218.

26. Eugene J, Dajee A, Kayaleh R, Gogia H, Dos Santos C, Gazzaniga A. Reduction pneumonoplasty for patients with a forced expiratory volume in 1 second of 500 milliliters or less. Ann Thorac Surg 1997; 63: 186-90 (discussion 190-192).

27. Teschler H, Thompson AB, Stamatis G. Short- and longterm functional results after lung volume reduction surgery for severe emphysema. Eur Respir J 1999; 13: 1170-1176.

28. Cassina PC, Teschler H, Konietzko N, Theegarten D, Stamatis G. Two-year results after lung volume reduction surgery in $\alpha_{1}$-antitrypsin deficiency versus smoker's emphysema. Eur Respir J 1998; 12: 1028-1032.

29. Weder W, Thurnheer R, Stammberger U, Burge M, Russi $\mathrm{E}$, Bloch K. Radiologic emphysema morphology is associated with outcome after surgical lung volume reduction. Ann Thorac Surg 1997; 64: 313-319 (discussion 319320).

30. The National Emphysema Treatment Trial Research Group. Rationale and design of the National Emphysema Treatment Trial (NETT): a prospective randomized trial of lung volume reduction surgery. $J$ Thorac Cardiovasc Surg 1999; 118: 518-528.

31. Meyers BF, Yusen RD, Lefrak SS, et al. Outcome of Medicare patients with emphysema selected for, but denied, a lung volume reduction operation. Ann Thorac Surg 1998; 66(2): 331-336.

32. Criner GJ, Cordova F, Furukaw S, et al. Prospective randomized trial comparing bilateral lung volume reduction surgery to pulmonary rehabilitation in severe chronic obstructive pulmonary disease. Am J Respir Crit Care Med 1999; 160: 2018-2027.

33. Geddes D, Davies M, Koyama H, et al. Effect of lungvolume-reduction surgery in patients with severe emphysema. N Engl J Med 2000; 343: 239-245.

34. Brenner M, McKenna RJ Jr, Gelb A, Fischel R, Wilson A. Rate of FEV1 change following lung volume reduction surgery. Chest 1998; 113: 652-659.

35. Fein A. Lung volume reduction surgery: answering the crucial questions. Chest 1998; 113 (Suppl. 14): 277S$282 \mathrm{~S}$.

36. Miller JIJ, Lee R, Mansour K. Lung volume reduction surgery: lessons learned. Ann Thorac Surg 1996; 61: 1464-1468 (discussion 1468-1469).

37. Naunheim K, Ferguson M. The current status of lung volume reduction operations for emphysema. Ann Thorac Surg 1996; 62: 601-612.

38. Ingenito E, Evans R, Loring $\mathrm{S}$, et al. Relation between preoperative inspiratory lung resistance and the outcome of lung-volume-reduction surgery for emphysema. $N$ Engl J Med 1998; 338: 1181-1185. 